\title{
Anatomical Evaluation of a Technique for Suprascapular Nerve Blockade
}

\author{
Chiara Concina1, Matthew Szarko², Eyeyemi Pearse1, Duncan Tennent ${ }^{1 *}$ \\ ${ }^{1}$ Shoulder Unit, Department of Orthopedics, St. George's Hospital, London, UK \\ ${ }^{2}$ Anatomy Department, St. George's University of London, London, UK \\ Email: "duncan@tennent.net
}

Received 24 June 2014; revised 11 August 2014; accepted 26 August 2014

Copyright ( 2014 by authors and Scientific Research Publishing Inc.

This work is licensed under the Creative Commons Attribution International License (CC BY). http://creativecommons.org/licenses/by/4.0/

(c) (i) Open Access

\begin{abstract}
Introduction: Analgesia following shoulder surgery commonly uses interscalene nerve blockade. When contraindicated (i.e. respiratory compromise), suprascapular nerve blockade can provide a viable alternative. Although a number of techniques have been used, Barber in 2005 described a simple method using anatomical landmarks. While theoretically straightforward, substantive evidence supporting the advantages attributed to the technique has yet to be identified. The present study anatomically examines the technique proposed by Barber to critically assess its potential to benefit clinical practice. Materials and Methods: Using the technique proposed by Barber in 2005, the Nevaiser portal was used to introduce a K-wire into the supraspinous fossa in the region of the suprascapular nerve. A spinal needle was inserted in the same manner and left in position in the presumed region of the transverse scapular ligament. Tissue was dissected out around the wire and needle to visualize their proximity to the suprascapular nerve and transverse scapular ligament respectively. Results: The K-wire was consistently located close to the suprascapular nerve with all cases being within $5 \mathrm{~mm}$. Spinal needle placement relative to the transverse scapular ligament was variable with $50 \%$ anterior, $25 \%$ posterior, and $25 \%$ displaced (likely due to dissection). Conclusions: The results illustrate that it is possible to reliably place a needle close to the suprascapular nerve using the technique described by Barber in 2005. This study provides anatomical confirmation of Barbers description of a simple technique and the basis for clinical study.
\end{abstract}

\section{Keywords}

Suprascapular Nerve, Nerve Block, Shoulder Pain

\footnotetext{
${ }^{*}$ Corresponding author.
} 


\section{Introduction}

Pain relief after shoulder surgery is a recognized problem. Local anesthetic nerve blockade is accepted as the optimum method and interscalene blockade as the gold standard [1]. It is recognized that this blockade may present with complications including nerve injury, pneumothorax and phrenic nerve palsy [2]-[4]. Alternative approaches to analgesia such as continuous wound infiltration, intra-articular catheterization and suprascapular nerve blockade have been used to optimise post operative pain relief [5]-[7]. In particular, suprascapular nerve blockade has been suggested to provide satisfactory analgesia, though not as effective as the interscalene block [1].

The suprascapular nerve derives from the superior trunk of the brachial plexus and typically receives motor and sensory fibres from the fifth and sixth cervical nerves [8]. While the suprascapular nerve provides motor supply to two of the four muscles of the rotator cuff, by Hilton's Law, the nerve also provides some sensory supply to the capsule of the shoulder joint [9]. The course of the nerve runs lateral beneath the trapezius and omohyoid muscles and enters the supraspinous fossa through the suprascapular notch, below the transverse scapular ligament [8].

A number of techniques have been described including the use of anatomical landmarks scapular divisions, and ultrasound to identify the suprascapular notch [5] [10] [11]. The landmarks can be complicated and the ultrasound technique to identify the suprascapular notch requires additional expertise and equipment. The rate of identification of the nerve using ultrasound can be as low as 36\% [12]. Barber [13] described a technique for local anesthetic blockade of the nerve based on very simple anatomical landmarks. While the technique appeared to be advantageous due to its simplicity the study did not include substantive anatomical or clinical evidence with which they could demonstrate the efficacy of their technique.

The present investigation aimed to utilize the technique suggested by Barber [13] and demonstrate anatomically, the relationship between the needle placement described by this technique and the suprascapular nerve as well as the transverse scapular ligament.

\section{Materials and Methods}

Eight cadavers preserved with phenol and glycerol to maintain tissue consistency similar to an in vivo condition were dissected (4 left and 4 right). All material was ethically obtained and utilized in accordance with the Human Tissue Act of 2004.

The technique proposed by Barber [13] was used as described below.

The tip of the coracoid was identified with a finger and the region described by the posterior border of the clavicle, the medial border of the acromion and the anterior border of the scapular spine was identified. A fingerbreadth medial to the acromial edge is the "Neviaser" portal used arthroscopically [14].

The Neviaser portal was identified medial to the medial border of the acromion, behind the posterior aspect of the clavicle. The tip of the coracoid was palpated and a 19 gauge spinal needle inserted into the supraspinous fossa aiming perpendicular until the bone at the base of the fossa was reached. The needle was then walked anteromedially until it passed off the bone. The path was traced back until the needle was on bone again in the fossa. This marked the point at which local anesthetic would be injected. A $1.6 \mathrm{~mm}$ K-wire was passed along same track into the bone and the needle removed.

A second needle was inserted in the same manner and left in position off the medial aspect of the bone in the presumed region of the transverse scapular ligament (Figure 1).

The skin and subcutaneous fat were dissected out around the wire and needle. The clavicle was dissected free of its superior and posterior attachments and the acromioclavicular joint and coraco-clavicular ligaments were divided. This enabled the clavicle to be retracted anteriorly, exposing the base of the coracoid fully. If necessary the supraspinatus muscle belly was mobilized posteriorly to improve visualization.

The transverse scapular ligament was located and the course of the suprascapular nerve explored (Figure 2 and Figure 3).

\section{Results}

In each dissected shoulder (case) the relationship of the spinal needle to the transverse scapular ligament was identified. The relationship of the K-wire to the suprascapular nerve in the supraspinous fossa was also measured (Table 1). 


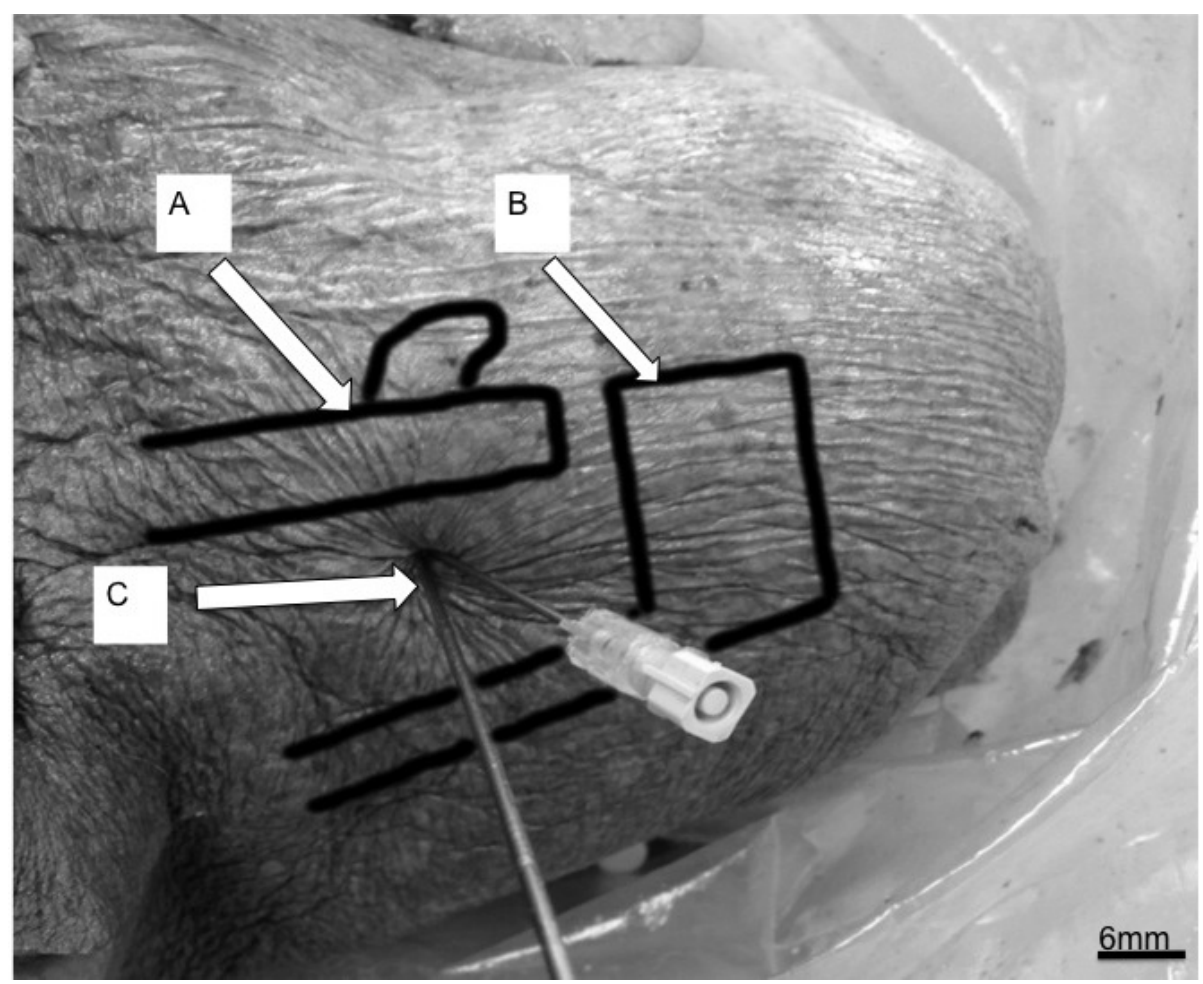

Figure 1. Dissection of a right shoulder demonstrating the relationship of the transverse scapula ligament, the suprascapular nerve and the markers. (A) Clavicle; (B) Acromion; (C) K-Wire and Needle placed in Neviaser's portal.

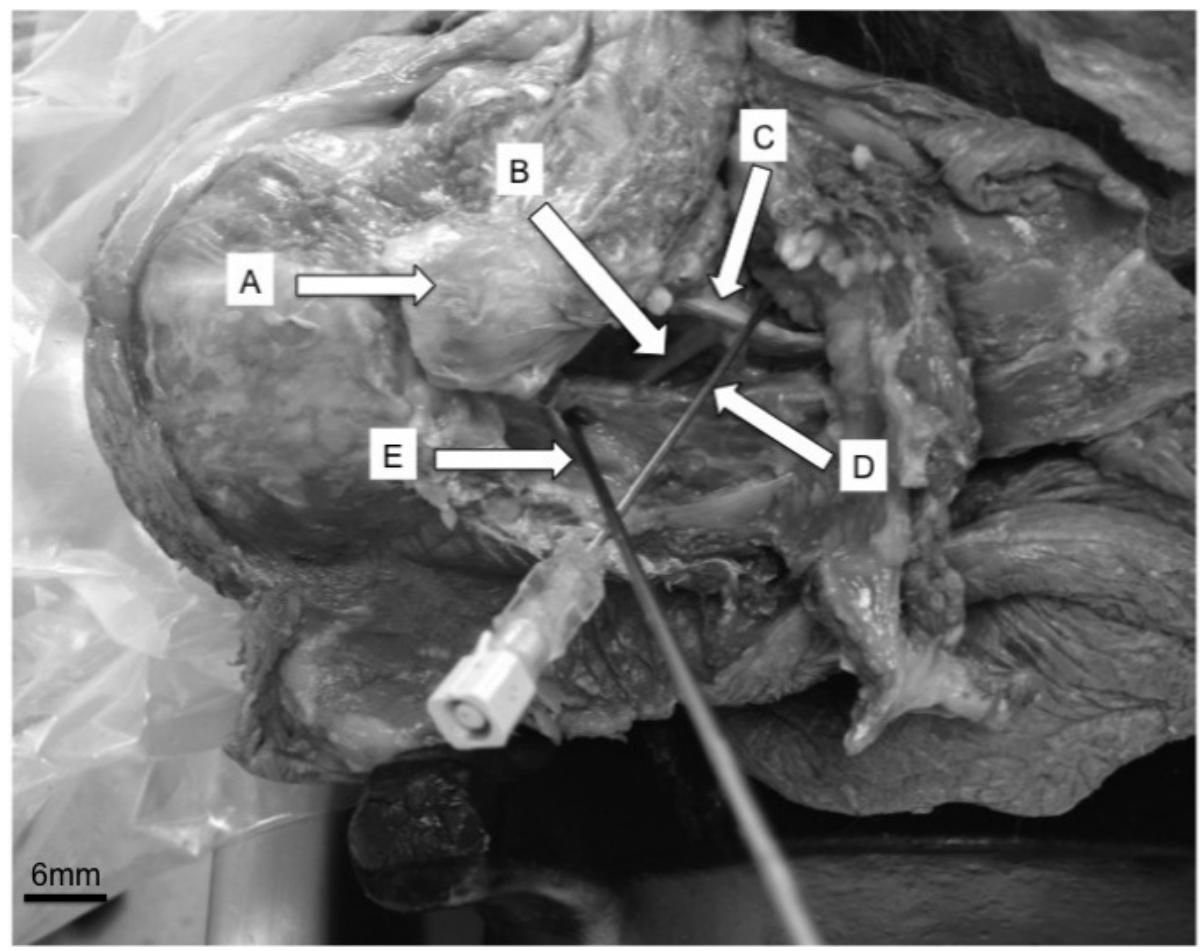

Figure 2. Image of a dissected left shoulder after performing the procedure suggested by Barber [13]. (A) Acromion; (B) Suprascapular nerve; (C) Transverse scapular ligament; (D) Needle anterior to transverse scapular ligament; (E) K-Wire in the supraspinatus muscle. 




Figure 3. Right shoulder dissection after performing the procedure suggested by Barber [13]. (A) Suprascapular nerve; (B) K-Wire within supraspinous fossa; (C) Supraspinatus muscle; (D) Needle located posterior to transverse scapular ligament.

Table 1. Table describing the final relationship of the spinal needle to the transverse scapular ligament and the K-wire to the suprascapular nerve.

\begin{tabular}{rcc}
\hline Case & Spinal needle location relative to transverse scapular ligament & K-wire location relative to suprascapular nerve \\
\hline case 1 & Anterior, in contact & $2 \mathrm{~mm}$ anterior \\
case 2 & Posterior in notch & $<5 \mathrm{~mm}$ anterior \\
case 3 & Posterior in notch & $<5 \mathrm{~mm}$ anterior \\
case 4 & Needle displaced & $5 \mathrm{~mm}$ anterior \\
case 5 & Posterior in notch & $<\mathrm{mm}$ anterior \\
case 6 & Needle displaced & $<5 \mathrm{~mm}$ anterior \\
case 7 & Posterior in notch & $2 \mathrm{~mm}$ anterior \\
case 8 & Anterior, in contact & $2 \mathrm{~mm}$ anterior
\end{tabular}

The spinal needle was found to be located posterior to the transverse scapular ligament and within the scapular notch in $50 \%$ of needle placements $(n=4) .25 \%$ of needle placements $(n=2)$ were located anterior and in contact with the transverse scapular ligament, and the needle was found to be displaced in $25 \%(n=2)$ of needle placements. The displacement of the needle was likely due to the process of dissection.

The K-wire was placed consistently close to the suprascapular nerve. There were small variations in needle placements with $37.5 \%$ of cases $(n=3)$ being $2 \mathrm{~mm}$ from the nerve, $37.5 \%$ of cases $(\mathrm{n}=3)$ greater than $5 \mathrm{~mm}$ from the nerve, and $25 \%$ of cases $(\mathrm{n}=2) 5 \mathrm{~mm}$ from the nerve.

\section{Discussion}

Pain relief after shoulder surgery has been investigated extensively. The interscalene nerve block has repeatedly been shown to produce the best analgesia [1] but, like any procedure, is not without its limitations. The procedure can be performed either with or without the use of Ultrasound, however it can be time consuming and does 
have complications. Nerve injury, pneumothorax, phrenic nerve palsy have all been reported and contraindications include any patients with respiratory compromise [2]-[4]. Anecdotally, patients also often find the ensuing complete sensory and motor brachial plexus blockade following interscalene nerve block is unpleasant. Alternative techniques, involving selective blockade of individual nerves rather than the whole upper trunk have been described. Although not providing comparable pain relief they have fewer side effects and complications. A number of techniques have been described to locate the suprascapular nerve [1] [5] [10]. Some of these use ultrasound and some are based on anatomical landmarks. The technique described by Barber [13] is simple and the author described positive results however these were not supported by any anatomical or clinical validation.

This study attempted to identify the anatomical relationship between the needle placement described by this technique and the suprascapular nerve as well as the transverse scapular ligament.

The suprascapular nerve arises from the upper trunk of the brachial plexus. It passes through the suprascapular notch in the scapula, medial to the base of the coracoid. It traverses the supraspinous fossa where it supplies the supraspinatus before coursing around the spine of the scapula and entering the infraspinous fossa where it gives off its terminal branches to the infraspinatus. There is some sensory supply to the skin over the shoulder but this is variable. Hilton's Law states that the sensory supply to the capsule of a joint is provided by the nerves that supply the muscles crossing the joint. The shoulder joint is crossed by the Deltoid muscle and Teres Minor (axillary nerve), Subscapularis (upper \& lower subscapular nerves) as well as supraspinatus and infraspinatus (suprascapular nerve). Complete analgesia of the shoulder will only be provided by blockade of the upper trunk of the brachial plexus. This is achieved by the interscalene block but, as previously discussed, it is not without complications. Whilst only partial analgesia is obtained by blockade of the suprascapular nerve is has been demonstrated to be an effective alternative.

The reliably close K-wire placement in relation to the suprascapular nerve validates the claims of Barber [13] to provide a simple, consistent technique to provide suprascapular nerve blockade. The slightly variable placement does not negatively affect the technique as Barber [13] describes infiltrating $20 \mathrm{ml}$ of local anesthetic into the supraspinous fossa. With the needle placed within $5 \mathrm{~mm}$ of the suprascapular nerve the local anesthetic will fully envelop it ensuring anesthetic blockade.

The results illustrate that it is possible to reliably place a needle close to the suprascapular nerve using the technique described by Barber [13]. This study provides anatomical confirmation of Barbers description of a simple technique and the basis for clinical study. The authors would recommend that consideration is given to using this simple and anatomically reproducible technique if suprascapular nerve blockade is being used.

\section{Acknowledgements}

The authors would like to acknowledge and thank the donors of the cadaveric tissue used in this study. Their generous donation helps enhance the safety and efficacy of clinical practice.

\section{Conflict of Interest}

The authors have no conflicts of interest involved with this study.

\section{References}

[1] Singelyn, F.J., Hotel, L. and Fabre, B. (2004) Pain Relief after Arthroscopic Shoulder Surgery: A Comparison of Intraarticular Analgesia, Suprascapular Nerve Block, and Interscalene Brachial Plexus Block. Anesthesia Analgesia, 99, 589-592. http://dx.doi.org/10.1213/01.ANE.0000125112.83117.49

[2] Seltzer, J.L. (1977) Hoarseness and Horner’s Syndrome after Interscalene Brachial Plexus Block. Anesthesia Analgesia, 56, 585-586.

[3] Flowers, G.A. and Meyers, J.F. (2004) Pseudoaneurysm after Interscalene Block for a Rotator Cuff Repair. Arthroscopy, 20, 67-69. http://dx.doi.org/10.1016/j.arthro.2004.04.048

[4] Benumof, J.L. (2000) Permanent Loss of Cervical Spinal Cord Function Associated with Interscalene Block Performed under General Anesthesia. Anesthesiology, 93, 1541-1544. http://dx.doi.org/10.1097/00000542-200012000-00033

[5] Ritchie, E.D., Tong, D., Chung, F., Norris, A.M., Miniaci, A. and Vairavanathan, S.D. (1997) Suprascapular Nerve Block for Postoperative Pain Relief in Arthroscopic Shoulder Surgery: A New Modality. Anesthesia Analgesia, 84, 1306-1312.

[6] Gottschalk, A., Burmeister, M.A., Radtke, P., Krieg, M., Farokhzad, F., Kreissl, S., Strauss, M. and Standl, T. (2003) 
Continuous Wound Infiltration with Ropivacaine Reduces Pain and Analgesic Requirement after Shoulder Surgery. Anesthesia Analgesia, 97, 1086-1091. http://dx.doi.org/10.1213/01.ANE.0000081733.77457.79

[7] Savoie, F.H., Field, L.D., Jenkins, R.N., Mallon, W.J. and Phelps, R.A. (2000) The Pain Control Infusion Pump for Postoperative Pain Control in Shoulder Surgery. Arthroscopy, 16, 339-342. http://dx.doi.org/10.1016/S0749-8063(00)90076-8

[8] Moore, K.L., Dalley, A.F. and Agur, A.M.R. (2013) Clinically Oriented Anatomy. 7th Edition, Lippencott_Williams \& Wilkins, Philadelphia, 693-707.

[9] Vorster, W., Lange, C.P., Briët, R.J., Labuschagne, B.C., du Toit, D.F., Muller, C.J. and de Beer, J.F. (2008) The Sensory Branch Distribution of the Suprascapular Nerve: An Anatomic Study. Journal of Shoulder and Elbow Surgery, 17, 500-502. http://dx.doi.org/10.1016/j.jse.2007.10.008

[10] Matsumoto, D., Suenaga, N., Oizumi, N., Hisada, Y. and Minami, A. (2009) A New Nerve Block Procedure for the Suprascapular Nerve Based on a Cadaveric Study. Journal of Shoulder and Elbow Surgery, 18, 607-611. http://dx.doi.org/10.1016/j.jse.2009.01.005

[11] Parris, W.C. (1990) Suprascapular Nerve Block: A Safer Technique. Anesthesiology, 72, 580. http://dx.doi.org/10.1097/00000542-199003000-00041

[12] Siegenthaler, A., Moriggl, B., Mlekusch, S., Schliessbach, J., Haug, M., Curatolo, M. and Eichenberger, U. (2012) Ultrasound-Guided Suprascapular Nerve Block, Description of a Novel Supraclavicular Approach. Regional Anesthesia and Pain Medicine, 37, 325-328. http://dx.doi.org/10.1097/AAP.0b013e3182409168

[13] Barber, F.A. (2005) Suprascapular Nerve Block for Shoulder Arthroscopy. Arthroscopy, 21, 1015.e1-1015.e4

[14] Neviaser, T.J. (1987) Arthroscopy of the Shoulder. Orthopedic Clinics of North America, 18, 361. 
Scientific Research Publishing (SCIRP) is one of the largest Open Access journal publishers. It is currently publishing more than 200 open access, online, peer-reviewed journals covering a wide range of academic disciplines. SCIRP serves the worldwide academic communities and contributes to the progress and application of science with its publication.

Other selected journals from SCIRP are listed as below. Submit your manuscript to us via either submit@scirp.org or Online Submission Portal.
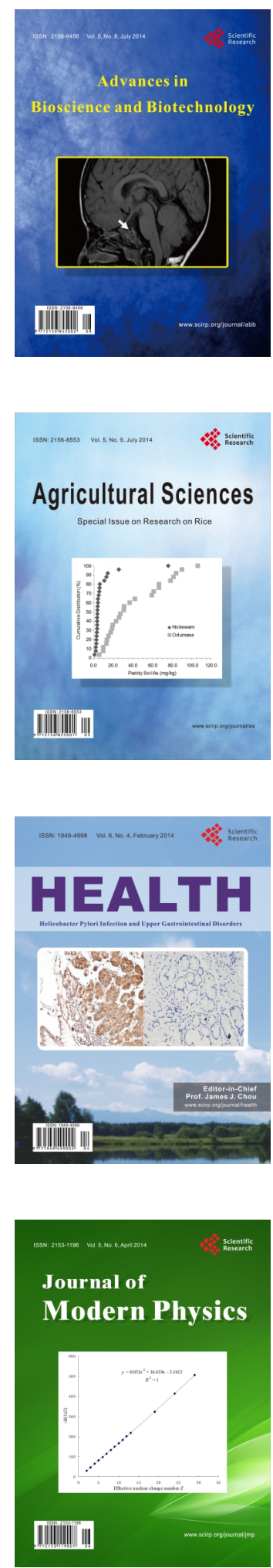
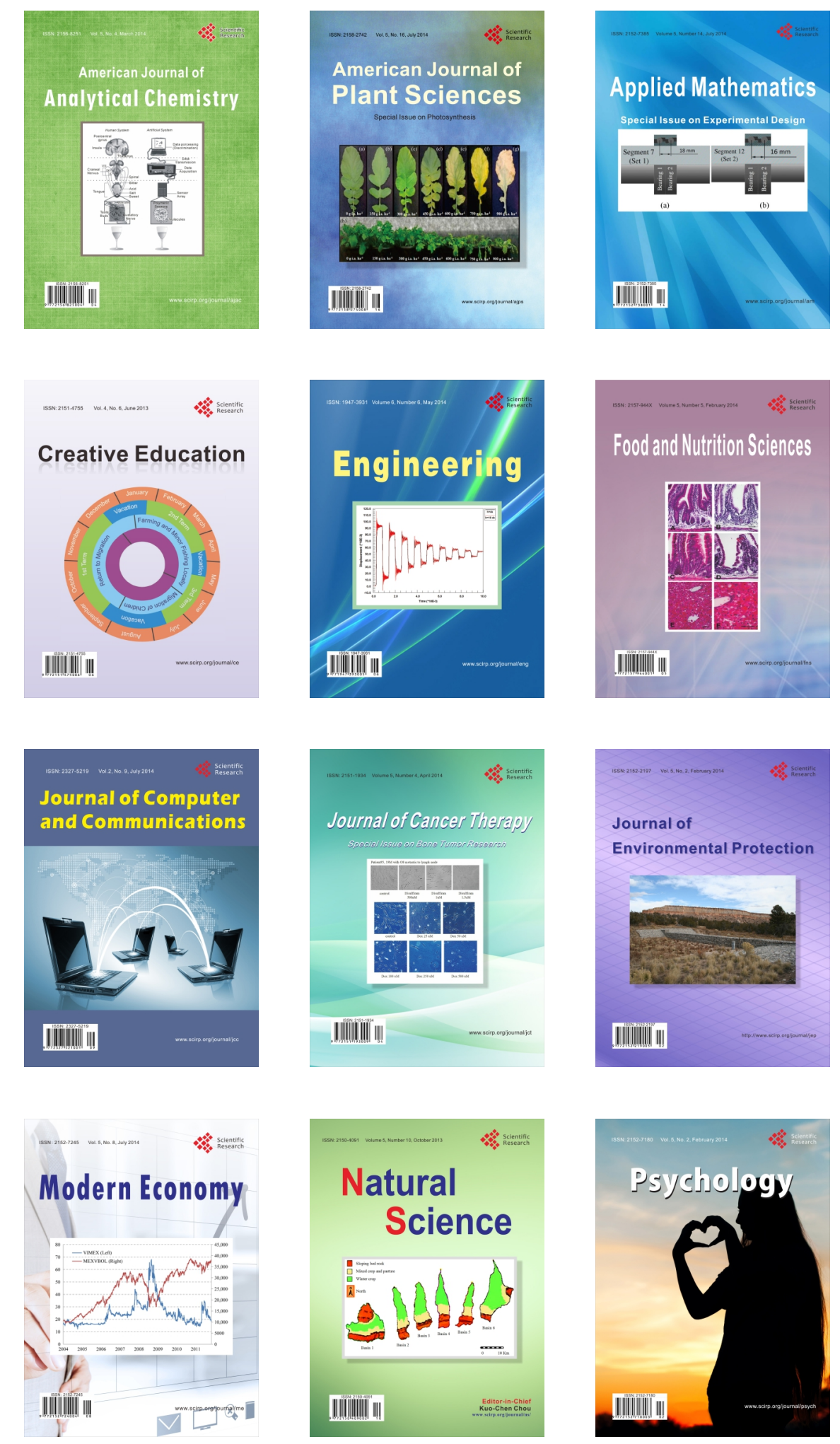